\title{
Extended opening hours in primary care: helpful for patients and-or- a distraction for health professionals?
}

\section{Richard Baker, Nicola Walker}

Department of Health Sciences, University of Leicester, Leicester, UK

Correspondence to Professor Richard Baker, Department of Health Sciences, College of Medicine, Biological Sciences and Psychology, University of Leicester, Centre for Medicine, University Road, LE1 7RH, UK; rb14@le.ac.uk

Accepted 24 June 2016 Published Online First 19 July 2016

\section{Sinked}

http://dx.doi.org/10.1136/ bmjqs-2016-005233

\section{CrossMark}

To cite: Baker $\mathrm{R}$, Walker N. BMJ Qual Saf 2017;26:347-349.
WHO regards access to primary care as a priority for all health systems, because of the benefits for population health and because of the changing nature of populations (more older people with chronic conditions) and the growing expectations of the public. ${ }^{1}$ In most developed countries, progress has been made in enabling people to use primary care services during routine office hours, and policymakers have begun to ask "how much access is enough"?

The two main drivers for extending access to general practices beyond traditional office hours are the possibility that longer opening hours would lead to reduced pressure on hospital services and the need for policy to respond to the pressure from patients for appointments with their primary care providers.

Difficulty in getting appointments in general practice is associated with higher use of hospital emergency departments, ${ }^{2}$ and evidence from a US study of extended hours in primary care indicates that extended hours can reduce the demand for care from hospitals. In a study relating to the years 2005-2008, a national sample of 43484 people with a usual source of care, $77.5 \%$ reported their provider offered care in the evening and weekend. ${ }^{3}$ Total expenditure per patient was $10 \%$ lower, and there were fewer emergency department attendances, among patients reporting access to extended hours. Evidence from England on the potential effect of weekend opening of general practices is likely to be emerging soon, and professionals and policymakers in this country will soon have to decide how much access to primary care is enough. Their conclusions are likely to be of interest to the primary care services of other countries.
The effect of extended hours may be dependent on other characteristics of the healthcare system; for example, if the capacity of primary care is already stretched, extending opening hours will simply spread the limited numbers of staff more thinly; increased access may serve to lower patients' thresholds for seeking care, leading to increased use of services without improvement in health or reducing pressure on hospital services. $^{45}$

\section{HELPFUL FOR A FEW PATIENTS}

There has also been uncertainty about the effect extended access would have on patient experience. An early study of an extended access scheme introduced in 2008 in England suggested that, in the first years of the scheme, satisfaction with opening hours improved only slightly. ${ }^{6}$ In this issue of the journal, Cowling and colleagues report a national study of the English scheme that provides more complete, and much needed, evidence on effects of extended access on patient experience. $^{7}$

In a previous study, ${ }^{8}$ the same group showed that patients who had an emergency hospital admission while registered to general practices with better access were more likely to be admitted via a general practitioner (GP) (vs an Accident and Emergency department). For each 5 -unit increase in the percentage of patients able to obtain a general practice appointment on their last attempt, the odds of admission to hospital via their GP (vs through the emergency department) increased by $15 \%$ (OR 1.15, 95\% CI $1.12 \%$ to $1.17 \%)$. While we do not know the 'head-to head advantages' of GP admission versus admission via the emergency department, better access to a 
GP has at least two possible advantages. First, GPs know their patients and may recognise when an admission is not required. This may be particularly true of frail elderly patients, whom emergency physicians may feel uncomfortable sending home, yet may in fact be better off staying in their home environment. Second, overcrowding of emergency departments constitutes a ubiquitous problem that has myriad adverse effects. So, having a route of admission to hospital that does not involve the emergency department has much to recommend it.

In their second study, ${ }^{7}$ Cowling and colleagues used a survey in which over 900000 respondents reported their experiences of 8005 general practices, and found that $79.9 \%$ of patients were very or fairly satisfied with the opening hours of their practices. There was a small association between participation in the scheme and patient satisfaction with opening hours, and even smaller, and inconsistent, associations with satisfaction with making an appointment and overall experience. However, the increase in satisfaction with opening hours associated with scheme participation was higher among employed respondents who were unable to take time off work to see a GP. Therefore, the extended access scheme has been helpful for some, but by no means all, patients.

The advantages for people in work should not be underestimated; it has been known for some years that they have greater difficulty than other groups in getting appointments with their GPs, ${ }^{9}$ and initiatives to improve access for them are fully justified. However, the overall impact of the scheme on patient satisfaction is modest at best.

There are several potential explanations. Many patients may regard other aspects of their care as more important, for example, seeing their preferred GP. ${ }^{10}$ The choice of GP is likely to be limited in an extended hours session where in most cases only one GP will be consulting. Other health professionals such as practice nurses can provide the appointments instead of, or alongside GPs seeing patients with less complex problems. The extra access offered by the scheme may have been too limited to make a real difference for patients. Under the scheme, the number of appointments a practice has to offer depends on their list size but individual sessions may only run for $30 \mathrm{~min}$ outside of routine opening hours. Perhaps a more ambitious scheme with longer opening hours would have more effect.

The extended hours scheme may not be appropriately designed to reduce emergency department use or hospital admissions as the appointments are required to be for routine problems and have to be booked in advance. Cowling's ${ }^{7}$ study does not report the effect of extended hours on use of emergency departments, hospital admissions, total costs or health outcomes, and therefore policymakers-and practices themselves-can only make provisional decisions about the place of extended hours access in primary care, and the amount of resources that can be justifiably allocated to them.

\section{A DISTRACTION FOR PROFESSIONALS?}

But the scheme could also be a distraction for primary care teams, the distractions increasing as the opening hours are increased. There are questions about the ability of general practice to sustain extended access during the week, and at weekends. To provide access beyond routine office hours, practices have to fund additional staff time, including ancillary services such as receptionists as well as clinical staff to be present. In an already stretched service, which in some areas is struggling to recruit and retain GPs, general practice is likely to need more convincing that extending opening hours at all, or even further, is clinically worthwhile and financially viable. With other pilots of extended hours failing to attract patients to their service, especially on weekends, ${ }^{11}$ it must be asked whether all general practices should take part in the scheme.

Even then, the question on how additional resources for primary care should be used remains to be answered. In many areas of England, general practices are under considerable strain. In those areas where the demand for care most exceeds the capacity of general practice to respond, would additional resources be better used in increasing the numbers of staff providing care during routine hours? If extended or weekend working is required of all practices by policymakers, will inequalities in healthcare be created, unless significant funding is provided to the areas with greatest demand?

Extended opening hours also run the risk of reducing continuity and increasing the fragmentation of care. The spread of staff over a longer period of the week would make some staff less accessible during the week; lower continuity is associated with higher hospital admission rates, ${ }^{12}$ and there could be an adverse effect on hospital use rather than a reduction, as hoped. GPs are in short supply, and the need to have longer opening hours without being able to employ more doctors is likely to lead to the provision of more care by non-medical staff (healthcare assistants, nurses and so on). A greater role for non-medical staff in providing general practice care is already expected to occur in order to meet the demands for more care, ${ }^{13}$ but this development has implications. There is potential for care to become more fragmented from the patient's perspective, as they consult different members of the healthcare team for different problems, and it is not yet clear that patients have agreed that their ability to see a doctor should, increasingly, depend on whether a non-medical intermediary approves their request. When launched in 1948, the National Health Service made it possible for people to consult a medically trained health professional about any health symptom that concerned them. Increasingly, this is not possible in 2016. 


\section{A MESSAGE FOR POLICYMAKERS}

Practice teams and policymakers need good quality evidence to help them make effective decisions on these issues. The paper published in this issue of the journal provides some of the answers, but it also highlights the failure of policymakers to ensure that evidence on the effectiveness of schemes such as extended access is obtained. The final conclusions from the prime minister's GP access fund will help to improve the evidence available on the effects of different amounts of extended opening. Further detailed investigation involving practices and their patients is required to understand whether current extended access services are succeeding in what they set out to achieve.

Cowling and colleagues' analysis has appeared 7 years after the launch of the scheme, and was completed by a group of enterprising researchers who realised that evidence was lacking. Policymakers should not rely on evidence about the value of their bright ideas to be provided in this way. Proactive commissioning of independent research at the same time as schemes are launched would improve the efficiency of the health system and help policymakers become better decision makers. The recent dispute in England over the introduction of a new contract for junior hospital doctors to enable 7-day working in hospitals is another example of how evidence and policy are often not brought together. In that case, the evidence was contested and the opportunity to set up thoroughly evaluated pilots was missed. It's just possible the emerging evidence on the extended access scheme, and on the more recent prime minister's GP access fund, ${ }^{14}$ will enable a better informed decision to be made about the implementation of 7-day opening in general practice in England.

Competing interests None declared.

Provenance and peer review Commissioned; internally peer reviewed.

\section{REFERENCES}

1 World Health Organisation. World Health Report 2008. Primary Health Care, now more than ever. Geneva: WHO, 2008.
2 Bankart MJG, Baker R, Rashid A, et al. Characteristics of general practices associated with emergency admission rates to hospital: a cross-sectional study. Emerg Med J 2011;28:558-63.

3 Jerant A, Bertakis KD, Fenton JJ, et al. Extended office hours and health care expenditures: a national study. Ann Fam Med 2012;10:388-95.

4 Rosen R. Meeting need or fuelling demand? Improved access to primary care and supply-induced demand. London: Nuffield Trust, 2014.

5 Centre for Reviews and Dissemination. Enhanced access in primary care settings. University of York, 2015.

6 Morgan CL, Beerstecher HJ. Satisfaction, demand, and opening hours in primary care: an observational study. $\mathrm{Br} \mathrm{J}$ Gen Pract 2011;61:e498-507.

7 Cowling TE, Harris M, Majeed A. Extended opening hours and patient experience of general practice in England: multilevel regression analysis of a national patient survey. BMJ Qual Saf 2016; doi:10.1136/bmjqs-2016-005233

8 Cowling TE, Harris M, Watt $\mathrm{H}$, et al. Access to primary care and the route of emergency admission to hospital: retrospective analysis of national hospital administrative data. BMJ Qual Saf 2016;25:432-40.

9 Baker R, Boulton M, Windridge $\mathrm{K}$, et al. Interpersonal continuity of care: a cross-sectional survey of primary care patients' preferences and their experiences. Br J Gen Pract 2007;57:283-90.

10 Turner D, Tarrant C, Windridge K, et al. Do patients value continuity of care in general practice? An investigation using stated preference discrete choice experiments. J Health Serv Res Policy 2007;12:132-7.

11 Pulse. Quarter of PM's seven-day GP access pilots have cut opening hours. 2015. http://www.pulsetoday.co.uk/yourpractice/practice-topics/access/quarter-of-pms-seven-day-gpaccess-pilots-have-cut-opening-hours/20010391.article\# . VZVUxflVhBc

12 Purdey S, Huntley A. Predicting and preventing avoidable hospital admissions: a review. J R Coll Physicians Edinb 2013;43:340-4.

13 Primary Care Workforce Commission. The future of primary care. Creating teams for tomorrow. Chair: Roland M. London: Health Education England, 2015.

14 Mott MacDonald. Prime Minister's Challenge Fund: Improving Access to General Practice. First Evaluation Report. 2015. NHS England Publication Gateway Reference Number 04123. https://www.england.nhs.uk/wp-content/uploads/2015/ 10/pmcf-wv-one-eval-report.pdf (accessed 14 Jun 2016). 